
\title{
25 Research Soure \\ Isocitrate dehydrogenase of Bacillus cereus is involved in biofilm formation
}

\author{
Linlin Zhao \\ Henan University \\ Qing Liu \\ Henan University \\ Qiubin Huang \\ Henan University \\ Fengying Liu \\ Henan University \\ Huiping Liu \\ Henan University \\ Gang Wang ( $\nabla$ gwangbio@henu.edu.cn ) \\ Henan University https://orcid.org/0000-0002-7410-0966
}

\section{Research Article}

Keywords: Bacillus cereus, Biofilm, Krebs cycle, IDH

Posted Date: April 2nd, 2021

DOl: https://doi.org/10.21203/rs.3.rs-370160/v1

License: (c) (1) This work is licensed under a Creative Commons Attribution 4.0 International License. Read Full License

Version of Record: A version of this preprint was published at World Journal of Microbiology and Biotechnology on November 1st, 2021. See the published version at https://doi.org/10.1007/s11274-02103175-3. 


\section{Abstract}

Tricarboxylic acid cycle (TCA cycle) is a central carbon metabolism pathway in prokaryotes and eukaryotes, and involved in matter metabolism and energy production. Isocitrate dehydrogenase (IDH), which is a key enzyme in the TCA cycle, participates in the formation of biofilms in Staphylococcus aureus by regulating the redox state inside the cell.

At present, it remains to be clarified whether IDH is involved in the formation of Bacillus cereus biofilms. In this study, we found a gene icdH annotated as encoding IDH in the $B$. cereus genome, and cloned and expressed the protein encoded by this gene. The enzyme activity assay showed that the protein had IDH

activity dependent on $\mathrm{NADP}^{+}$, indicating that this gene encoded an IDH. The mutant $\triangle i c d H$ was obtained by gene knockout. Phenotypic analysis showed that the biofilm yield and sporulation rate of the mutant $\Delta i c d H$ decreased. To reveal the role of IDH in biofilm formation, extracellular $\mathrm{pH}$ and citric acid content were measured. The results showed that a B.cereus $0-9$ strain that lacked IDH exhibited accumulation of citric acid and acidification of the extracellular matrix. Given that citric acid is a metal chelator, the accumulation of citric acid may lead to a lack of metal ions in cells, resulting in reduced cell viability and affecting biofilm formation. Consistent with this hypothesis, the addition of excess $\mathrm{Fe}^{3+}$ restored biofilm formation in the mutant. These results suggest that IDH in B.cereus may regulate biofilm formation by modulating intracellular redox homeostasis. In addition, we found that the $i c d H$ deletion of $B$. cereus $0-9$ resulted in the destruction of the stage I of sporulation process, and thus resulted in a reduced sporulation rate, which was significantly different from sporulation in $B$. subtilis caused by interruption of the stage I sporulation process due to icdH loss.

\section{Introduction}

During long-term evolution, in response to a variety of environmental stresses, many Bacillus species have developed various adaptations and adopted protective strategies to improve their survival ability by sensing changes in the conditions inside and outside the cell, such as swarming motility, metabolic enzyme production, and biofilm formation (Bais HP et al. 2004). It has been reported that biofilms are special structured bacterial communities with highly organized structures and matrix components (Branda SS at al. 2001). These cell communities are bound together mainly by an extracellular matrix that is secreted by itself composed of exopolysaccharide and protein, which are biosynthesized via the products encoded by the operon epsA-O (henceforth simply eps) and the terminal gene tasA of $y q x \mathrm{M}$ sipW-tasA operon (henceforth simply sipW), respectively ((Branda SS at al. 2006 and Frances C et al. 2008). Biofilms are capable of increasing adhesion on biotic and abiotic surfaces, as well as resisting several kinds of environmental stresses, including nutrient deficiency and oxidative stress, which enhances plant root colonization and biological control efficiency (llana KG et al. 2013). Studies have shown that the formation of biofilms is a very complex process and the environmental impact is especially important in this process, for instance, the $\mathrm{pH}$ of the environment, nutrient composition, temperature, osmotic pressure, iron concentration and surface characteristics of the contact medium 
(Tang $\mathrm{H}$ et al. 2006). In natural environment, more than $90 \%$ of microorganisms exist in the form of biofilms. Research on biofilms has become a hot spot. For instance, Tantan, Gao et al proposed that the ptsH gene influences biofilm formation; $\mathrm{U}$. Venkateswara Prasad et al suggested that phosphorylation controls biofilm formation (Gao TT et al. 2019 and Prasad UV. 2015).

Nitrogen and carbon sources are essential for the survival of bacteria, while the TCA cycle, also known as the Krebs cycle, is a ubiquitous metabolic pathway in aerobic organisms (Lynne $S$ et al. 2014). Various important intermediates formed in the pathway provide a large number of biosynthetic carbon sources. In addition, the thioester bond of succinyl-CoA generated by the two oxidative decarboxylation of TCA cycle hydrolyzes under the action of succinatethiokinase and generates a large amount of ATP, which provides energy for the activities of living organisms; the final metabolic pathway for three major nutrients (sugars, lipids and amino acids), crucial for the metabolism and transformation of these nutrients; and the method of reoxidation of fermentation products, which also has a certain impact on the living environment of bacteria. IDH is an important enzyme in the TCA cycle that can catalyze the oxidative decarboxylation of isocitrate to form $\mathrm{CO}_{2}, \mathrm{H}_{2} \mathrm{O}$, and a-ketoglutarate, and reduce $\mathrm{NAD}^{+}$or NADP ${ }^{+}$to NADH or NADPH, respectively (Zhang YJ et al. 2018). According to the spatial characteristics, IDH is generally classified into two types, namely, NAD-IDH and NADP-IDH. IDH is also divided into two types according to the degree of molecular polymerization: monomers, with a molecular weight of approximately 40-50 kD, and homodimers, with a molecular weight of approximately 80-100 kD (Kaori S and Yasuhiro T. 2016). Both monomeric IDH and dimeric IDH play a vital role in bacterial biosynthesis, energy metabolism, and antioxidant stress. IDH is also a critical intersection point between the TCA cycle and the glyoxylate shunt. The reversible phosphorylation of NADH-dependent IDH can switch the two pathways by changing carbon flow. Furthermore, isocitrate can be catalytically converted to glyoxylate and succinate, and IDH plays an important role in the glyoxylate shunt (Lv PP. 2017).

It has been reported that in $S$. aureus, IDH is involved in the formation of biofilms by regulating the redox state in vivo (Prasad UV et al. 2015). However, the role of IDH in the TCA cycle in biofilm formation of $B$. cereus remains unknown. We studied the effect of IDH on biofilm formation in $B$. cereus $0-9$ (GenBank: $\mathrm{CP} 042874.1)$. B. cereus $0-9$ is a gram-positive endophytic bacterium that was isolated from wheat roots in our laboratory, which is easily cultured, can form strong biofilms and generate spores in harsh environments, and exhibits favorable swimming ability. In our published papers, $B$. cereus 0-9 was shown to have the ability to control wheat sheath blight, exhibiting potential application value and good control effects (Zhang JM et al. 2020b). We investigated the relationship between IDH from the TCA cycle and biofilms based on gene knockout and complementation, protein induction and purification, enzyme activity determination and other techniques.

\section{Materials And Methods}

\section{Strains, plasmids, media, and growth conditions}


The properties, function and cultured conditions of B. cereus 0-9, E.coli BL21(DE3), E.coli 116(pir+) and E.coli GM2163(dam-) have been reported in the previous article. The plasmids pMAD, pMADCHI, pET28a and pAD123-pgal properties and application have also been described in published paper (Zhang JM et al. 2020 C). All strains were stored at $-80^{\circ} \mathrm{C}$. The mutant strains and complementary strains were routinely cultured at $30^{\circ} \mathrm{C}$ in Luria-Bertani (LB) liquid medium ( $1 \%$ peptone, $1 \% \mathrm{NaCl}, 0.5 \%$ yeast extract; $\mathrm{pH} 7.0$ ) overnight. When necessary, some antibiotics were added to the culture medium at the following concentrations: $3 \mu \mathrm{g} / \mathrm{ml}$ erythromycin for $B$. cereus growth or $100 \mu \mathrm{g} / \mathrm{ml}$ ampicillin and $50 \mu \mathrm{g} / \mathrm{ml}$ kanamycin for $E$. coli growth (Karen L et al. 2013). The ingredients and proportions of LBS medium which was used for biofilm formation experiment was detailed in the published article (Zhang JM et al. 2020a).

\section{Strains construction}

The icdH gene (locus. FRY47_22620هdeletion mutant strain $(\Delta i c d H)$ in $B$. cereus 0-9 was constructed using homologous recombination strategy ( $X u Y$ et al. 2014). Two fragments for allelic exchange which were amplified with primeSTAR polymerase (purchased from Takara company) from 0-9 genomic DNA using primers were digested with the corresponding restriction endonuclease enzyme, and then were inactivated with metal bath at $80^{\circ} \mathrm{C}$ for 10 minutes. Two fragments were linked to the PMAD with corresponding double enzymes digestion. The PMAD-based plasmid constructs were transferred into the E. coli 116 receptor state to clone by the heat shock transformation method (Sha $J$ et al. 2011). To verify the correctness of the cloned DNA fragment, Plasmids were digested by enzymes and amplified by PCR. The plasmid containing the correct DNA fragment was cloned into E. coli GM2163 by electroporation (1.2 $\mathrm{kV}$, Bio-Rad) (Lu YP et al. 2012). After being purified again, the plasmid was transformed into competent cells of $B$. cereus $0-9$. After cultured at $30^{\circ} \mathrm{C}$ for $1 \mathrm{~h}$ with $10000 \mathrm{rpm}$, the cells were spread on LB agar plates. After incubation at $30{ }^{\circ} \mathrm{C}$ overnight, the plates were screened for blue and white colonies, and the correct clones were obtained. All the strains derived from $B$. cereus 0-9 were constructed according to the method described above. All primers were listed in Table 1.

\section{Analysis of biofilm formation}

For analysis of solid surface-associated biofilm formation, the crystal violet staining method with some modifications was used ( $\mathrm{Si}$ T et al. 2016). A single colony of B. cereus $0-9$ and its mutant strain was inoculated into $5 \mathrm{ml}$ of LB medium and inoculated at $30^{\circ} \mathrm{C}$ overnight. About $50 \mu \mathrm{l}$ of the overnight culture was inoculated into $2 \mathrm{ml}$ of LBS medium (peptone $10 \mathrm{~g}$, yeast extract $5 \mathrm{~g}$, sodium citrate $1 \mathrm{~g}, \mathrm{NaCl} 5 \mathrm{~g}$, ammonium sulfate $2 \mathrm{~g}, \mathrm{MgSO}_{4} \cdot 7 \mathrm{H}_{2} \mathrm{O} 0.2 \mathrm{~g}, \mathrm{~K}_{2} \mathrm{HPO}_{4} 14 \mathrm{~g}, \mathrm{KH}_{2} \mathrm{PO}_{4} 6 \mathrm{~g}$, and glucose $1 \mathrm{~g}$, in per liter of distilled water) in glass culture tubes with a diameter of $0.8 \mathrm{~cm}$. The tubes were incubated in an upright position at $30^{\circ} \mathrm{C}$ for 7 days before surface pellicles and cultures were carefully removed from the tubes. The biofilm culture method of the strain and the specific test method were detailed in our previous paper (Zhang JM et al.2020c). Each sample examination was repeated three times. The same procedure was used for 24-well polystyrene board for testing of biofilm.

\section{Confocal laser scanning microscope (CLSM) analysis}


The biofilms were observed by confocal laser scanning microscopy as previously described with some modifications (Olympus FV1000) (Bayjuinov PO et al. 2018). The biofilm culture method should refer to the above method. The difference is that about $50 \mu \mathrm{l}$ of overnight culture which was adjusted to the same $\mathrm{OD}_{600}$ value was inoculated into $2 \mathrm{ml}$ of LBS medium in a glass-bottom cell culture dish (Cat. No: 801002; $₫ 15 \mathrm{~mm}$, purchased from Benxin Biology). The cell culture dishes were statically cultured in a horizontal position at $30^{\circ} \mathrm{C}$ for 6 days. Each sample examination was repeated five times. Finally, the LBS medium was slowly removed with a pipette (Gao T et al. 2015). As the liquid itself contained expressed fluorescent proteins, the formation of biofilms could be monitored by CLSM through the bottom of the cell culture dish. The biofilm images were analyzed by ZEN lite software (blue edition). Images were obtained from random positions on the biofilms formed on the cell culture dish. Confocal stack images were used to determine the thickness of the biofilms.

\section{Protein overexpression and purification}

The construction of icdH expression vectors and protein purification were followed as our published article with some modifications was used (Zhang JM et al. 2020c). The open reading frame of $i c d H$ gene was amplified from $B$. cereus $0-9$ genome DNA. The correct fragment which had been verified by sequencing was ligated with the pET28a vector, to obtain the recombinant plasmids. After being verified by double enzyme digestion, the recombinant plasmid was transformated into E. coli BL21 (DE3). The recombinant IcdH protein was expressed in E. coli BL21 (DE3) strains according to a previous method described (Diethmaier et al. 2014). When E. coli BL21 (DE3) which harboured expression plasmids was cultivated to logarithmic phase, $100 \mu \mathrm{M}$ isopropyl- $\beta$-D-thiogalactopyranoside (IPTG) was added for being induced for $4 \mathrm{~h}$ at $37^{\circ} \mathrm{C}$. The cells were harvested by centrifugation and were lysed by sonication (Hayashi T et al. 2014). After lysis, the crude extracts were centrifuged at 12,000 rpm for a minimum of 60 min.

Protein purification was based on our previously published method (Zhang JM, 2014c). The purified recombinant proteins were stored at $-20^{\circ} \mathrm{C}$. Protein purity was determined by $12 \%$ SDS-PAGE (Kobayashi M and Takada Y. 2014).

\section{Assay for IDH enzyme activity}

IDH enzyme activity was carried out as reported previously with some modifications (Ochiai T et al. 1979). The enzyme activity of IDH was carried out at $25^{\circ} \mathrm{C}$ in 96-well microplates. $1 \mathrm{ml}$ of enzyme activity reaction mixture contained $20 \mathrm{mM}$ Tris-HCl buffer ( $\mathrm{pH} 8.0), 1.0 \mathrm{mM} \mathrm{DL}$-isocitrate, $2 \mathrm{mM} \mathrm{MnCl} 2$ or $\mathrm{MgCl}_{2}$, and $1.0 \mathrm{mM} \mathrm{NADPH}$. An appropriate amount of enzyme was added to the reaction mixture at the initial reaction stage, $200 \mu \mathrm{l}$ of reaction mixture was added to 96 -well microplates. The NADPH curve was detected at $340 \mathrm{~nm}$ with a thermostatted Cary $300 \mathrm{UV}$-vis spectrophotometer (Varian, USA). The molar extinction coefficient was $6.22 \mathrm{mM}^{-1} \mathrm{~cm}^{-1}$. The protein concentrations were monitored with a Bio-Rad Protein Assay Kit (Bio-Rad, USA). Bovine serum albumin was used as a standard. The final data was the 
average of at least three duplicates. The amount of enzyme that reduced $1 \mu \mathrm{mol}$ of NADPH per minute was considered one unit of enzyme activity.

\section{Determination of citric acid}

The citric acid content was determined by using a citric acid content determination kit purchased from Suzhou Keming Biotechnology Company Limited. (www.Cominbio.com).

\section{Determination of spore rate}

The spore ratios of $B$. cereus $0-9$ and its mutant were determined for details as our published article (Zhang JM et al. 2020b).

\section{Determination of florescence intensity}

The fluorescence intensity of the strain was determined according to a previously reported method (Saeid $\mathrm{H}$ et al. 2016). The $B$. cereus strain $0-9$ and its mutant strain containing the sipW-GFP reporter gene were incubated overnight in $5 \mathrm{ml}$ of LB medium at $30^{\circ} \mathrm{C}$ with shaking at $220 \mathrm{rpm}$. About $1 \mathrm{ml}$ of overnight culture was inoculated into $100 \mathrm{ml}$ of LBS medium and incubated at $30^{\circ} \mathrm{C}$ with shaking at $220 \mathrm{rpm}$. After $24 \mathrm{~h}$, the cells were collected by centrifugation at $4^{\circ} \mathrm{C}$ and $12000 \mathrm{rpm}$ and washed three times with $\mathrm{ddd}_{2} \mathrm{O}$, and then, were suspended in $1 \mathrm{ml}$ of $\mathrm{ddH}_{2} \mathrm{O}$. Suspensions with the same $\mathrm{OD}_{600}$ value were added to 96 well microplates and examined with a microporous plate-type multifunctional detector (blue, $490 \mathrm{~nm}$ ). The normalized fluorescence intensity was determined as the ratio of fluorescence intensity to $\mathrm{OD}_{600}$. Each data point represents the average value of three independent experiments.

\section{Results}

\section{The deletion of $i c d H$ gene decreases biofilm formation of B.cereus 0-9}

There have been many reports on the role of TCA cycle in Bacillus spp. For example, Wang DX et al proposed that effects of TCA cycle on the grown and pectinase activity of Bacillus licheniformis DY2 (Du $X$ et al 2019); Liu ZY et al showed TCA cycle regulated bacitracin production of Bacillus licheniformis DW2 (Liu ZY et al.2018). However, the reports on the role of isocitrate dehydrogenase in B. cereus are relatively few until now. Therefore, the $i c d H$, an encoding gene of IDH from $B$. cereus $0-9$, was knocked out according to the above described double-exchange methods, and the mutant strain $\Delta i c d H$ was successfully constructed. The differences in biofilm formation in LBS medium were particularly significant when comparing $\Delta i c d H$ and B. cereus 0-9 (Fig. 1A). The mutant strain $\Delta i c d H$ showed a $50 \%$ decrease in biofilm formation compared to $B$. cereus $0-9$ through crystal violet staining, and the results are shown in Fig. 1B.

At the same time, the microplates-based method was used to observe the phenotype of the solid biofilms. Polystyrene 24-well microplates were used in this study $(\Phi, 15.6 \mathrm{~mm}$, purchased from Corning). It was observed that when grown in LBS medium, $B$. cereus 0-9 formed a large amount of floating biofilms, 
which were closely connected to the surface of the petri dish to form a complete overall floating object that was dense and thick. However, the mutant strain $\Delta i c d H$ produced a small amount of dispersed biofilms floating on the surface of the dish (Fig. 2). The biofilms produced by $B$. cereus $0-9$ and the mutant strain $\triangle i c d H$ on the microporous plates were quantitatively analyzed by a crystal violet staining assay. The results were consistent with the above results. The mutant strain $\Delta i c d H$ showed less biofilm formation than $B$. cereus $0-9$, displaying only $50 \%$ of the biomass of $B$. cereus $0-9$ biofilms. The above results showed that the $i c d H$ gene deletion decreased biofilm formation of bacillus cereus 0-9.

\section{Complementention of $i c d H$ gene restored biofilm formation of mutant to the wild type level}

From the above biofilm measurement results, it was clear that, under the same conditions, when cultured in LBS medium, the amount of biofilm formed by $\Delta i c d H$ was much lower than that of $B$. cereus $0-9$. Therefore, we wondered whether deletion of the $i c d H$ gene directly affected biofilm formation of $B$. cereus $0-9$. we constructed the complementation strain $\Delta i c d H$ :icdH and determined its biofilm production. As shown in Fig. 1 (A), biofilm formation of the complementary strain was approximately the same as that of $B$. cereus 0-9 in LBS medium, which recovered the $B$. cereus $0-9$ levels. The crystal violet staining data are listed in Fig. 1 (B), which showed that the complementation made up for the biofilm defects of the mutant strain $\Delta i c d H$. The crystal violet data indicated that the complementary strain made up for the biofilm defects caused by the defective strain $\Delta i s d H$.

We further verified whether loss of the $i c d H$ gene in $B$. cereus $0-9$ caused a reduction in biofilm formation. The known IDH gene from the genome of $B$. subtilis BS168 was cloned using the primers Bs168icdH overlap-s/Bs168icdHa; this gene shared high homology with the gene from $B$. cereus $0-9$. The complementation strain $\Delta i c d H: i c d H^{\mathrm{BS}}$ was constructed as above method. Biofilm formation experiments were also carried out in LBS medium. The result was the same as that of the complementary strains $\Delta i c d H$.icdH (Fig. 1A). The amount of biofilm formation of the complementary strain $\Delta i c d H:: i c d H^{B S}$ also recovered to the $B$. cereus $0-9$ level. The crystal violet staining data of the complementary strain $\Delta i c d H:: i c d H^{\mathrm{BS}}$ were similar to those of the complementary strain $\Delta i c d H:$ :icdH, which is not listed here. Based on the above result, we preliminarily confirmed that the deletion of isocitrate dehydrogenase $(i c d H)$ of the TCA cycle in Bacillus cereus 0-9 seriously affected the formation of biofilm.

\section{The deletion of $i c d H$ decreased the expression of genes encoding biofilm components}

To further demonstrate the effect of the $i c d H$ on biofilms, the fluorescent transcription fusion reporter strains $0-9\left(\mathrm{P}_{\text {sip } W}\right)$ and $\Delta i c d H\left(\mathrm{P}_{\text {sip } W}\right)$ were obtained. The formation of biofilms produced by the mutant $\triangle i c d H$ and $B$. cereus $0-9$ strains could be quantitatively detected using a microporous plate-type multifunctional detector (green, $450 \mathrm{~nm}$, GloMax Multi, USA). The fluorescence spectrophotometry results obtained after the strains were incubated in LBS medium for 10 days are listed in Table 2. Compared with the fluorescent transcription fusion reporter strain 0-9( $\left.P_{\text {sip }}\right)$, the GFP fluorescence intensity of the mutant strain $\Delta i c d H$ was only $43 \%$ that of reporter strain $0-9\left(\mathrm{P}_{\text {sip } W}\right)$. In addition, the absence of $i c d H$ also delayed the expression of genes related to the biofilm matrix. Under the same conditions, the GFP fluorescence of 
the fluorescent transcription fusion reporter strain 0-9( $\left.\mathrm{P}_{\text {sip } W}\right)$ could be detected for approximately $72 \mathrm{~h}$ under static culture conditions, while the mutant $\Delta i c d H\left(\mathrm{P}_{\text {sip } W}\right)$ needed approximately $216 \mathrm{~h}$. In the oscillatory culture, the expression of sipW could be detected in $0-9\left(\mathrm{P}_{\operatorname{sip} W}\right)$ for approximately $24 \mathrm{~h}$, and the mutant $\Delta i c d H\left(\mathrm{P}_{\text {sipW }}\right)$ needed approximately $72 \mathrm{~h}$. The above results suggested the deletion of the icdH gene was one of the factors leading to the decrease of genes encoding biofilm components expression.

\section{CLSM observation confirmed that icd $H$ deletion changes the structure of biofilms}

The biofilm morphology of the transcription fusion strains 0-9 $\left(\mathrm{P}_{\text {sip } W}\right)$ and $\Delta i c d H\left(\mathrm{P}_{\text {sip } W}\right)$ was observed under a two-photon laser confocal microscope (Olympus FV1000) 100-fold magnification after $120 \mathrm{~h}$ of culture in LBS medium, as shown in Fig. 3. Form Fig. 3(A) and 3(B), it showed that the biofilms of the mutant strain $\Delta i c d H$ that formed at the bottom of the plastic dish were noticeably thinner with numerous voids, similar to discrete units of bacteria. However, the $B$. cereus $0-9$ strain harboring the GFP reporter formed a thick layer of uniformly dense biofilms with porous channels but no obvious voids. Fig. 3(C) and $3(D)$ show stratified scan diagrams of the biofilms formed by strain $0-9\left(P_{\text {sip } W}\right)$ and the mutant strain $\Delta i c d H\left(\mathrm{P}_{\text {sip } W}\right)$. It can be seen that $0-9\left(\mathrm{P}_{\text {sip } W}\right)$ produced thicker biofilms than the mutant $\Delta i c d H\left(\mathrm{P}_{\text {sip } W}\right)$. The thickness of the biofilm produced by strain $0-9\left(P_{\text {sip } W}\right)$ was approximately $23 \mu \mathrm{m}$, while that of the mutant strain was only $6.72 \mu \mathrm{m}$. From the result, it was confirmed that $i c d H$ deletion could change the structure of biofilms.

\section{The icdH encoding protein is an isocitrate dehydrogenase}

The protein-expressing strain $\Delta i c d H$ was successfully obtained, and then, induced and purified according to the above experiment method. As shown in Fig. 4, the pure protein was approximately $46 \mathrm{kD}$ in size. The protein concentration was measured with the BSA-Bradford analysis method (Silvério SC et al. 2012). The activity of the newly purified enzyme was tested for $1 \mathrm{~h}$ according to the method described above for determination of IDH activity. When the purified protein concentration was $1.46 \mathrm{mg} / \mathrm{ml}$, and the average enzyme activity in an hour was $0.86 \mathrm{U} / \mathrm{ml}$. However, the activity of the inactivated control protein at the same concentration was only $0.15 \mathrm{U} / \mathrm{ml}$ under the same conditions. When the protein stock was diluted by a factor of 10 , the enzyme activity was still $0.78 \mathrm{U} / \mathrm{ml}$. On the basis of the above results, we found that the ICDH protein had the activity of IDH from the TCA cycle. The enzyme activity remained stable for approximately $24 \mathrm{~h}$. We confirmed that the missing gene in the mutant strain, $i c d H$, was the encoding gene of IDH from the TCA cycle in B. cereus $0-9$.

\section{IDH deficiency blocks the TCA cycle and causes citric acid accumulation}

The absence of $i c d H$ resulted in the downstream steps of the TCA cycle not proceeding normally, which would severely affect many metabolic processes in vivo. To verify this result, exogenous a-ketoglutarate acid at $0.001 \%$ was added to the mutant strain $\Delta i c d H$ cultured in liquid LBS medium. As we expected, the biofilm formation of the mutant strain $\Delta i c d H$ restore to the level of $B$. cereus $0-9$ to a certain extent. The results are shown in Fig. 5. The result fully demonstrated the important of $i c d H$ gene in the TCA cycle, and 
the deletion of $i c d H$ gene resulted in the blocking of downstream routes, thus affecting the formation of biofilm in the strain.

We speculated that the absence of $i c d H$ also led to the accumulation of large amounts of upstream citric acid while blocking the normal downstream route of the TCA cycle. The $\mathrm{pH}$ values of the $B$. cereus strain 0-9 and the mutant strain $\triangle i c d H$ cultured statically in LB and LBS media for 4 days at $30^{\circ} \mathrm{C}$ were tested. The results are listed in Fig. 6 . As expected, whether cultured in LB or LBS medium, the medium of the mutant strain $\Delta i c d H$ had a lower $\mathrm{pH}$ value, even though the LBS medium contained a buffer system. To further confirm our hypothesis, the citric acid content in the medium was determined using a citric acid assay kit. Under the same conditions, the citric acid content of the $B$. cereus strain 0-9, which was statically cultured in LBS medium for 4 days at $30^{\circ} \mathrm{C}$, was $3.889 \mu \mathrm{M} / \mathrm{L}$, while the citric acid content of the mutant strain $\Delta i c d H$ was $11.944 \mu \mathrm{M} / \mathrm{L}$. The citric acid content in the LBS medium in which the mutant strain $\Delta i c d H$ was incubated was nearly three times as high as that in the $B$. cereus 0-9 medium.

The above results were completely consistent with our hypothesis, it was showed that the damage of icdh gene in the TCA cycle leaded to the amounts of citric acid, which changed the $\mathrm{pH}$ value of the culture environment and inhibited the formation of biofilm.

\section{Supplementation of excess $\mathrm{Fe}^{3+}$ can restore biofilm formation in icdH mutants}

The lack of metal ions in cells would result in reduced cell viability and affect biofilm formation. Citric acid is a good chelating agent and can chelate with metal ions. The accumulation of citric acid may lead to increased iron ion chelation, resulting in a rapid decrease in the concentration of metal ions in the medium. To explore this hypothesis, different concentrations of exogenous iron ions were added to the LBS medium. Under the same culture conditions, biofilm formation experiments of B.cereus strain 0-9 and the mutant strain $\Delta i c d H$ were performed. The results are shown in Fig. 7. From the results, it can clearly be seen that the addition of exogenous iron ions at different concentrations led to different degrees of recovery defects in the formation of biofilms of the mutant strain $\Delta i c d H$.

\section{IDH affects the sporulation of Bacillus cereus}

In our previously studies, we found that the deletion of SodA1 could delay the spore formation of B.cereus, which suggested the level of ROS played an important role in the regulation of spore differentiation initiation (Zhang JM et al. 2020b). Therefore, we want to explore whether the function and activity of Redox related enzyme would affect spore formation. According to literature reports, after the $i c d H$ gene was knocked out in $B$. subtilis, the spore production rate of the mutant strain was nearly few (Wang H. et al. 2017). Therefore, the sporulation of the mutant strain $\Delta i c d H$ was tested. The test result is listed in Figure 8. To our surprise, the spore production rate of the mutant strain $\Delta i c d H$ was only second that of B.cereus 0-9. Under the same culture conditions, the spore production rate of the mutant strain $\Delta i c d H$ reached $63.63 \%$. However, the sporulation rate of $B$. cereus $0-9$ was only $80.54 \%$. According to this result, the roles of the $i c d H$ gene in $B$. subtilis was very different in that of $B$. cereus. 


\section{Discussion}

In this report, we found for the first time that the $i c d H$ gene from the TCA cycle of B.cereus 0-9 affected biofilm formation. Under certain conditions, $\triangle i c d H$, a mutant lacked the icdH gene, produced very little biofilm when cultured in LBS medium compared with B. cereus 0 -9. First, it was speculated that loss of $i c d H$ might affect the normal growth of the strains, causing differences in biofilms. To test this hypothesis, the growth of B.cereus 0-9 and $\triangle i c d H$ in LB and LBS media was monitored, but the growth curves of the two strains showed no differences. It is well known that in the TCA cycle, citric acid can be isomerized to form isocitric acid, which can form a-ketoglutaric acid under the action of IDH, and then, the cycle continues via subsequent steps. It was hypothesized that the absence of $i c d H$ might cause the failure of conversion of isocitric acid to a-ketoglutaric acid. And then, different concentrations of exogenous a-ketoglutaric acid were directly added to the LBS medium. Consistent with our prediction, the mutant strain showed restoration of the level of biofilm production to that of $B$. cereus 0-9 in LBS medium. The results fully demonstrated the importance of the $i c d H$ gene in the TCA cycle, and deletion of the $i c d H$ gene resulted in the blockade of downstream routes, thus affecting the formation of biofilms by the strain.

In addition, it had been reported that most bacteria needed a pH range of 7.0-8.0 to form biofilms (Gao TT et al. 2019 and llana KG et al. 2013). The accumulation of large amounts of citric acid may resulted in a change in $\mathrm{pH}$ in the culture environment and affected the formation of biofilms. The results of $\mathrm{pH}$ monitoring and citric acid content determination in the culture medium of $B$. cereus $0-9$ and $\Delta i c d H$ fully indicated that damage to the $i c d H$ gene from the TCA cycle led to citric acid accumulation, which changed the $\mathrm{pH}$ value of the culture environment and inhibited biofilm formation.

Iron ions are important for the function of heme-containing cytochromes, which play a crucial role in the respiratory organs of bacteria, and thus affecting the vitality of the cell (Gaballa et al. 2008). It has been shown in the literature that the bacterial cellular respiration chain affects the production of the bacterial biofilm matrix (Prasad UV et al.2015). Iron ions are an important component of the respiratory system, and the concentration of iron ions affects the cellular respiration chain function of the bacteria; therefore, the concentration of iron ions also affects the production of the bacterial biofilm matrix (Sarah DB et al. 2018). The literature suggests that a high concentration of $\mathrm{Fe}^{3+}$ is beneficial to the production of the biofilm matrix of bacteria, thus promoting biofilm formation (llana KG et al. 2013). However, a low concentration of iron ions may cause the loss of pigment function in cells, leading to impaired cellular respiration, thus reducing biofilm matrix production and biofilm formation. After adding different concentrations of exogenous $\mathrm{Fe}^{3+}$ in the LBS medium, the recovery of biofilm of $\Delta i c d H$ demonstrates deletion of $i c d H$ leads to the accumulation of citric acid, chelating a large of number $\mathrm{Fe}^{3+}$ and disrupting the normal operation of the respiratory system in the bacteria, and affects the biofilm formation. However, does $\mathrm{Fe}^{3+}$ affect biofilm formation through respiration in B.cereus? or how exactly? We don't know yet.

It has been reported that when $i c d H$ is deleted from the TCA cycle in S. aureus, the production of NADPH is hampered, which affects the redox balance in the cell, leading to impaired biofilm formation (Prasad 
UV et al. 2015). Additionally, it is reported that the spore formation process needs four stages, and the first major structural change in spore formation is misdivision (Liu Y et al. 2005). There are a lot of literatures that suggest the level of ROS played an important role in the regulation of spore differentiation initiation (Passalacqua KD et al. 2006). We hypothesized the deletion of $i c d H$ affected the intracellular redox balance, which could be the reason for the damage of spore formation in stage I. However, it has also been reported the $\mathrm{pH}$ value of the culture also affects the spore formation (David S. 1995). We cannot rule out that the deletion of $i c d H$ causes culture acidification that affects the spore differentiation initiation. We tried to find evidence that $i c d H$ deletion in $B$. cereus affects the imbalance, which will be confirmed in our subsequent research and also be confirmed in the future.

\section{Conclusions}

B. cereus $0-9$ is a widely distributed and strongly adaptable potential biocontrol strain. We found that the deletion of $i c d H$ encoding IDH in the $B$. cereus $0-9$ genome severely affected the formation of biofilms. Fluorescence and CLSM assay results of fusion reporting strains showed that the loss of icdH also delayed the initiation time of $B$. cereus $0-9$ biofilm formation and changed the morphology of the biofilms.Our evidence indicated that the absence of IDH in the TCA cycle led to the accumulation of citric acid, which changed the acidification of the culture environment of the strain. Furthermore, because of the chelation activity of citric acid, which hindered the normal absorption of metal ions inside bacteria, resulting in reduced cell viability and affecting biofilm formation. The above result showed that IDH from the TCA cycle may regulate biofilm formation by regulating the intracellular redox balance. In addition, we found that when IDH was lost in B. cereus $0-9$, the sporulation rate was reduced, which was significantly different from the stagnation of sporulation observed in $B$. subtilis due to interruption of the stage I sporulation process caused by icdHloss.

\section{Declarations}

\section{Acknowledgments}

This Study was funded by Science \& Technology Research and Development Project of Henan Province (212300410331). We thank Springer Nature Author Services for language modification.

\section{The author contributions}

Gang Wang, as the doctoral supervisor, guided the operation and writing of this experiment throughout, and participated in the citric acid determination experiment.

Linlin Zhao, the main experimentand author of this experiment, constructed the knockout strain and the complementary strain, and determined the influence of the gene on the biofilm, as well as the operation of various subsequent experiments.

Qing Liu was mainly involved in the purification of protein and the determination of enzyme activity. 
Qiubin Huang made biofilm slides and looked at the morphology under a confocal laser microscope.

Fengying Liu participated in the determination of fluorescence expression of transcriptional fusion strains.

Huiping Liu was involved in an experiment in which complementary strains restored biofilms.

\section{References}

Bais HP, Fall R, Vivanco JM (2004) Biocontrol of Bacillus subtilis against infection of Arabidopsis roots by Pseudomonas syringae is facilitated by biofilm formation and surfactin production. Plant Physiol 134: 307-19.

Bayjuinov PO, Dennis MO, Chien CS, Daniel JG, Matthew SJ, Fitzpatrick (2018) Modern Laser Scanning Confocal Microscopy. Curr Protoc Cytom 85: e39.

Branda SS, Chu F, Kearns DB, Losick R, and Kolter R (2006) A major protein component of the Bacillus subtilis biofilm matrix. Mol Microbiol 59: 1229-1238.

Branda SS, González-Pastor JE, Ben-Yehuda S, Losick R, and Kolter R (2001) Fruiting body formation by Bacillus subtilis. Proc Natl Acad Sci 98: 11621-11626.

David SJ and Sean PG (1995) Factors influencing the activity of taurolidine against spores of Bacillus subtilis. Int J Pharmaceut 126: 261-266.

Diethmaier C, Newman JA, Akos TK et al (2014) The YmdB phosphodiesterase is a global regulator of late adaptive responses in Bacillus subtilis. J bacterial 196: 265-275.

Du X, Wang DH, Yin D, Guan Y, Ye XY (2019) Exogenous Glucose Promotes Growth and Pectinase Activity of Bacillus licheniformis DY2 Through Frustrating the TCA cycle. Biotechnol Bioproc E 24: 942-953.

Frances C, Daniel BK, Maloon A, Chai YR, Kolter R and Losick R (2008) A novel regulatory protein governing biofilm formation in Bacillus subtilis. Mol Microbiol 68: 1117-1127.

Hayashi T, Matsuzaki W, Takada Y (2014) Characterization of chimeric and mutated isocitrate lyases of a mesophilic nitrogen-fixing bacterium, Azotobacter vinelandii, and a psychrophilic bacterium, Colwellia maris. Biosci Biotech Bioch 78: 195-201.

Ilana KG, Alexander K.W. Elsholz, Christine M, Peter R. Girguis, Roberto K, and Richard L (2013) Respiration control of multicellularity in Bacillus subtilis by a complex of the cytochrome chain with a membrane-embedded histidine kinase. Gene Dev 27: 887-899.

Gaballa A, Antelmann H, Aguilar C, Khakh SK, Song KB, Smaldone GT, Helmann JD. 2008. The Bacillus subtilis iron-sparing response is mediated by a Fur-regulated small RNA and three small basic proteins. 
Gao TT, Ding MZ, Yang CH, Fan HY, Chai YR, Li Y (2019) The phosphotransferase system gene ptsH plays an important role in MnSOD production, biofilm formation, swarming motility, and root colonization in Bacillus cereus 905. Res Microbiol 170: 86-96.

Gao T, Foulston L, Chai Y, Wang Q, Losick R (2015) Alternative modes of biofilm formation by plantassociated Bacillus cereus. Microbiology Open 4: 452-64.

Kaori S and Yasuhiro T (2016) Characterization of NADP+-dependent isocitrate dehydrogenase isozymes from a psychrophilic bacterium, Colwellia psychrerythraea strain 34H. Biosci Biotech Bioch 80: 14921498.

Karen L. Visick, Kevin P. Quirke, Sheila M. McEwen (2013) Arabinose Induces Pellicle Formation by Vibrio fischeri. Appl Environ Microb 79: 2069-2080.

Kobayashi M and Takada Y (2014) Effects of the combined substitutions of amino acid residues on thermal properties of cold-adapted monomeric isocitrate dehydrogenases from psychrophilic bacteria. Extremophiles 18: 755-762.

Liu Y, Qin YC, Pan BH (2005) Several crucial events in sporulation of Bacillus Subtilis. Chi B Life Sci 17: 360-363.

Liu ZY, Yu WL, Nomura CT, Li JH, Chen SW, Yang Y, Wang Q (2018) Increased flux through the TCA cycle enhances bacitracin production by Bacillus licheniformis DW2. Appl Microbiol Biot 102: 69356946.

Lu YP, Zhang C, Lv FX, Bie XM and Lu ZX (2012) Study on the electro-transformation conditions of improving transformation efficiency for Bacillus subtilis. Lett Appl Microbiol 55: 9-14.

Lv PP, Tang WG, Wang P, Cao ZY, Zhu GP (2017) Enzymatic characterization and functional implication of two structurally different isocitrate dehydrogenases from Xylella fastidiosa. Biotechnol Appl Bioc 65: 230-237.

Lynne S. Cairns, Laura H and Nicola R. Stanley W (2014) Biofilm formation by Bacillus subtilis: new insights into regulatory strategies and assembly mechanisms. Mol Microbiol 93: 587-598.

Ochiai T, Fukunaga N, and Sasaki S (1979) Purification and some properties of two NADP+ -specific isocitrate dehydrogenases from an obligately psychrophilic marine bacterium, Vibrio sp. strain ABE-1. J Biochem 86: 377-384.

Passalacqua KD, Bergman NH, Herring-Palmer A et al (2006) The superoxide dismutases of Bacillus anthracis do not cooperatively protect against endogenous superoxide stress. J Bacteriol 18: 3837-3848 
Prasad UV, Vasu D, Yeswanth S, Swarupa V, Sunitha MM, Choudhary A, and Sarma PVGK (2015) Phosphorylation controls the functioning of Staphylococcus aureus isocitrate dehydrogenase - favours biofilm formation. J Enzym Inhib Med Ch 30: 1-7.

Saeid H, Zeinolabedin TS, Seyed AMMS, Ali MB, Silvana N (2016) Effects of water stress and light intensity on chlorophyll fluorescence parameters and pigments of Aloe vera L. Plant Physiol Bioch 106: 141-148.

Sarah DB, Julia S, Ines DP, Henri DG, Hernalsteens JP, Herman G and Surbhi MK (2018) Enzymes Catalyzing the TCA- and Urea Cycle Influence the Matrix Composition of Biofilms Formed by MethicillinResistant Staphylococcus aureus USA300. Microorganisms 6: 113.

Sha J, Wang YL, Wang JC, Ren L, Tu Q, Liu WM, Wang XQ, Liu AJ, Wang L, and Wang JY (2011) Capillarycomposited microfluidic device for heat shock transformation of Escherichia coli. J Biosci Bioeng 112: 373-378.

Silvério SC, Sérgio M, Adriane MFM, Eugénia AM, José AT, Solange IM (2012) Interference of some aqueous two-phase system phase-forming components in protein determination by the Bradford method. Anal Biochem 421: 719-724.

Si T, Li B, Zhang K, Xu YR, Zhao HM, and Jonathan V. S (2016) Characterization of Bacillus subtilis Colony Biofilms via Mass Spectrometry and Fluorescence Imaging. J proteome Res 15: 1955-1962.

Tang H, Liu GS, Xie ZX, Sheng P (2006) Progress of Investigation on the Structure and Formation of Bacterial Biofilm. Amino acids and Biotic Resources 28: 30-33.

Wang H, Wang YX, Yang RJ (2017) Recent progress in Bacillus subtilis spore-surface display: concept, progress, and future. Appl Microbiol Biotechnol 101: 933-949.

Xu Y, Chen M, Zhang Y et al (2014) The phosphotransferase system gene pts/ in the endophytic bacterium Bacillus cereus is required for biofilm formation, colonization, and biocontrol against wheat sharp eyespot. FEMS Microbiol Lett 354: 142-152.

Zhang JM, Li M, Zhang YB, Sang LD, Liu Q, Zhao LL, Liu FY, Wang G (2020a) GapB Is Involved in Biofilm Formation Dependent on LrgAB but Not the Sinl/R System in Bacillus cereus 0-9. Front Microbiol 11: 591926.

Zhang JM. Wang HD, Huang QB, Zhang Y, Zhao LL, Liu FY, Wang G (2020b) Four superoxide dismutases of Bacillus cereus 0-9 are non-redundant and perform diferent functions in diverse living conditions. World J Microb Biot 36: 12.

Zhang JM. Wang HD, Xie T, Huang QB, Xiong X, Liu Q, Wang G (2020c) The YmdB protein regulates biofilm formation dependent on the repressor SinR in Bacillus cereus 0-9. World J Microb Biot 36: 165. 
Zhang YJ, Corné S, Saleh A, Federico S, Jiang L, Toshihiro O, Alexander G, Alisdair RF (2018) The extrapathway interactome of the TCA cycle: expected and unexpected metabolic interactions. Plant Physiol 177: 966-979.

\section{Tables}

Table 1 Primers used in this study

\begin{tabular}{|c|c|}
\hline Primer & Sequence $₫ 5^{\prime} \rightarrow 3^{\prime}$ end $\rrbracket$ \\
\hline icdH-up-BamHI-s & ACACGGATCCCGCTTGTACTTCATGCAGATCA \\
\hline icdH-up-Xhol-a & CACACTCGAGGGTACATTCATAACACCATTAG \\
\hline$i c d H-d-X h o l-s$ & ACACCTCGAGATTAAAAACATGGATGTAGCGA \\
\hline$i c d H-d-E c o R I-a$ & CACAGAATTCTCATTTCAACTAAAGAAGCTGC \\
\hline icdHpro-lap-Mlul-s & ACACACGCGTGATTAGAAACTTTGAAAAGTTAC \\
\hline icdHpro-lap-a & GTCAATGTGATAACCCCCATGACATTCTCTССTTTTCCTGAAAATTC \\
\hline icdHorf-lap-s & CAGGAAAAGGAGAGAATGTCATGGGGGTTATCACATTGACGAC \\
\hline icdHorf-lap-Xhol-a & CACACTCGAGTTATGCGTTTTTGATTATCGCTAC \\
\hline PicdH-EcoRI-s & ACACGAATTCGATTAGAAACTTTGAAAAGTTAC \\
\hline PicdH-overlap-a & АTTTTTTCACСTTGTGCCACCATGACATTCTCTССTTTTCCTGA \\
\hline 168icdHoverlap-s & GAAAAGGAGAGAATGTCATGGTGGCACAAGGTGAAAAAATTACAG \\
\hline 168icdH Xhol-a & CACACTCGAGTTAGTCCATGTTTTTGATCAGTTC \\
\hline icdHcom-Xhol-a & CACACTCGAGTTATGCGTTTTTGATTATCGCTAC \\
\hline$g f p-X h o l-a$ & ACACGGATCCATGACGACAGGTGAAAAAATTACTG \\
\hline PsipW-BamHI-s & CACACTCGAGTTATTTGTATAGTTCATCCATGCCA \\
\hline PsipW-gfp-a & CACAGGATCCGTGAAAGTAATAAGTGTTGGGA \\
\hline \multirow[t]{2}{*}{$g f p-P \operatorname{sip} W-s$} & AGTTCTTCTCCTTTACTCATCGTCTCTCTCССTCTCCGTTGTTTTA \\
\hline & AACGGAGAGGGAGAGAGACGATGAGTAAAGGAGAAGAACTTTTC \\
\hline icdHcom-Xhol-a & AC \\
\hline \multirow[t]{2}{*}{ icdHorf-28a-BamHI-s } & CACACTCGAGTTATGCGTTTTTGATTATCGCTAC \\
\hline & ACACGGATCCATGACGACAGGTGAAAAAATTACTG \\
\hline
\end{tabular}


Table 2 The fluorescence intensity of transcription fusion strains $0-9\left(\mathrm{P}_{\text {sip } W}\right)$ and $\Delta i c d H\left(\mathrm{P}_{\operatorname{sip} W}\right)$.

\begin{tabular}{|ll|}
\hline Bacteria Name & Fluorescence Intensity \\
\hline The B.cereus 0-9 & $\begin{array}{l}7.923 \\
\mathrm{e}^{2} \pm 0.008\end{array}$ \\
\hline $\begin{array}{l}\text { The B.cereus } 0-9 \text { harboring GFP } \\
\text { reporter }\end{array}$ & $8.621 \mathrm{e}^{3} \pm 0.15$ \\
\hline $\begin{array}{l}\text { The mutant } \Delta \text { icdH harboring GFP } \\
\text { reporter }\end{array}$ & $3.704 \mathrm{e}^{3} \pm 0.15$ \\
\hline
\end{tabular}

Each data represents the average value of three independent experiments.

Figures 


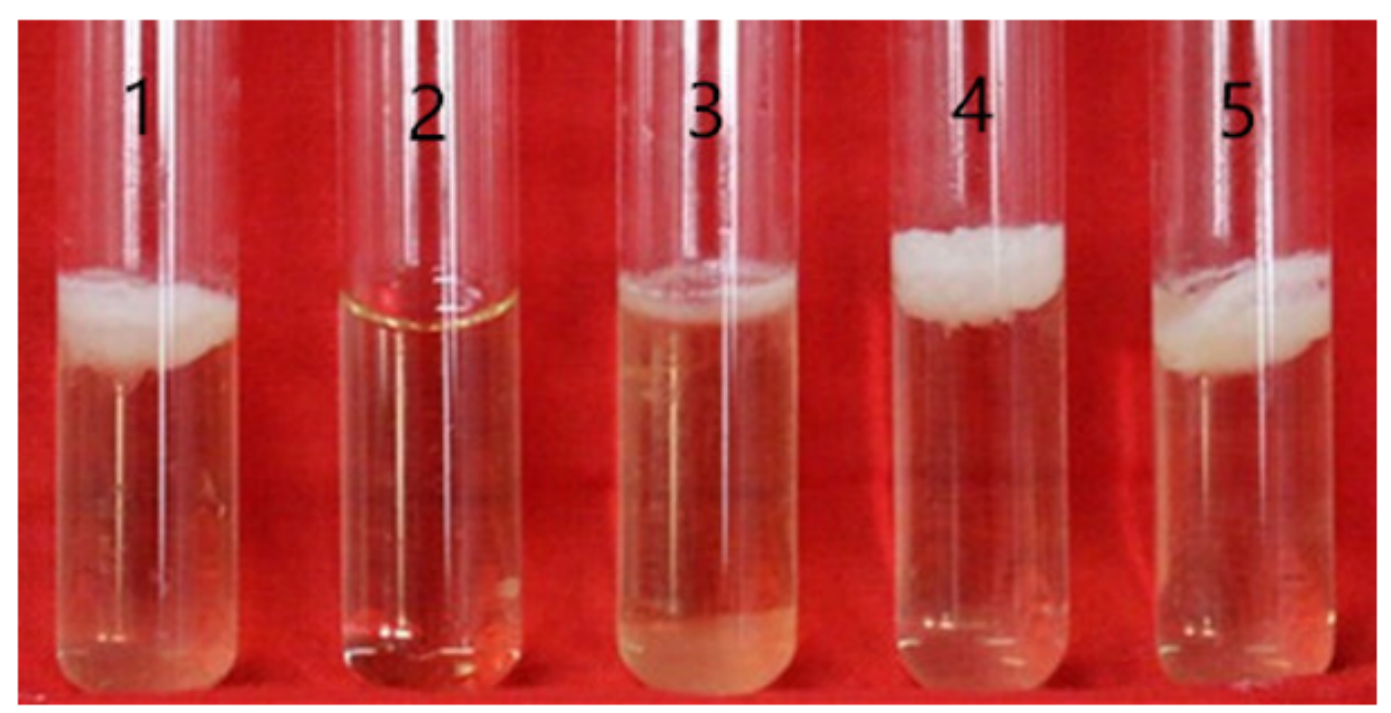

a

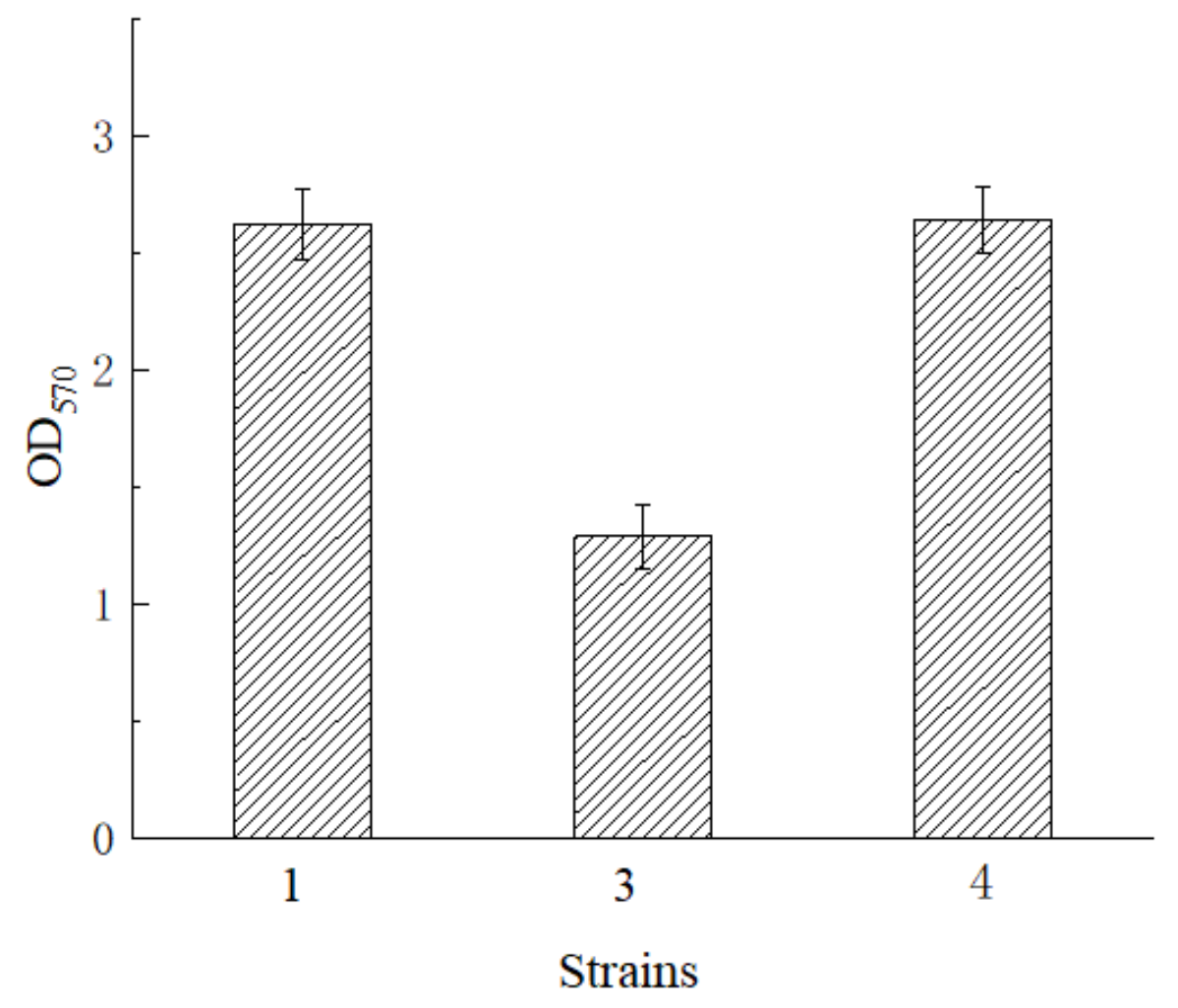

\section{Figure 1}

The amount of biofilm produced in the glass tubes by B.cereus $0-9$ and mutant strain $\triangle \mathrm{icdH}$ when cultured in LBS medium for 5 days. 1: B.cereus 0-9 2: Blank 3: $\Delta i c d H ~ 4: \Delta i c d H:: i c d H ~ 5: ~ \Delta i c d H:: i c d H B S$. Notes: (A) The developed results of the strains in the membrane of glass. (B) The crystal violet staining results of the biofilm corresponding to the tested strains. Each bar represents mean and standard deviations of the mean of all the measurements 


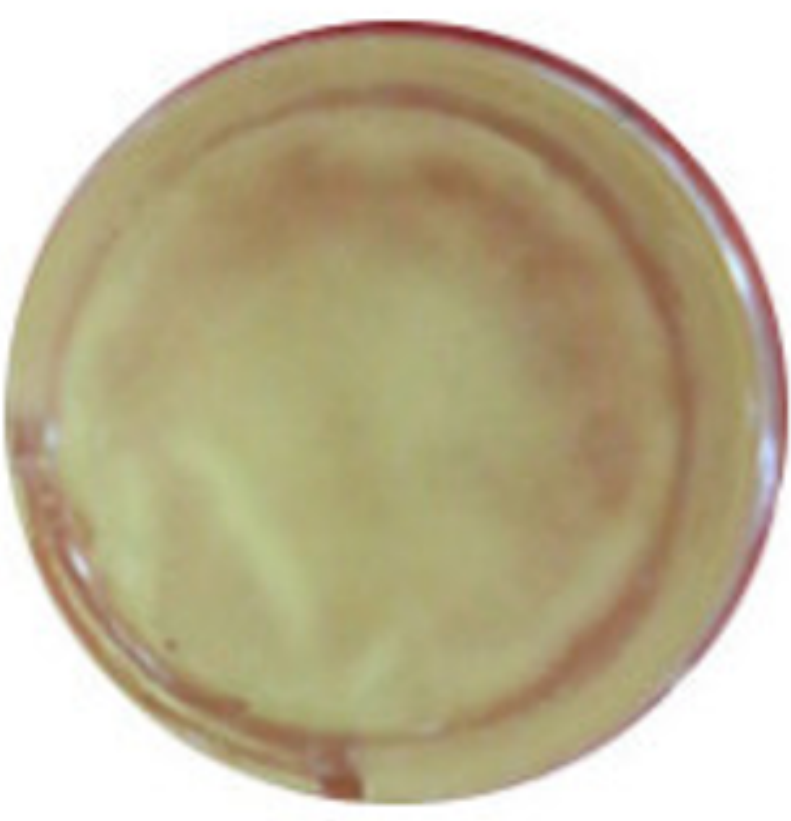

(1)

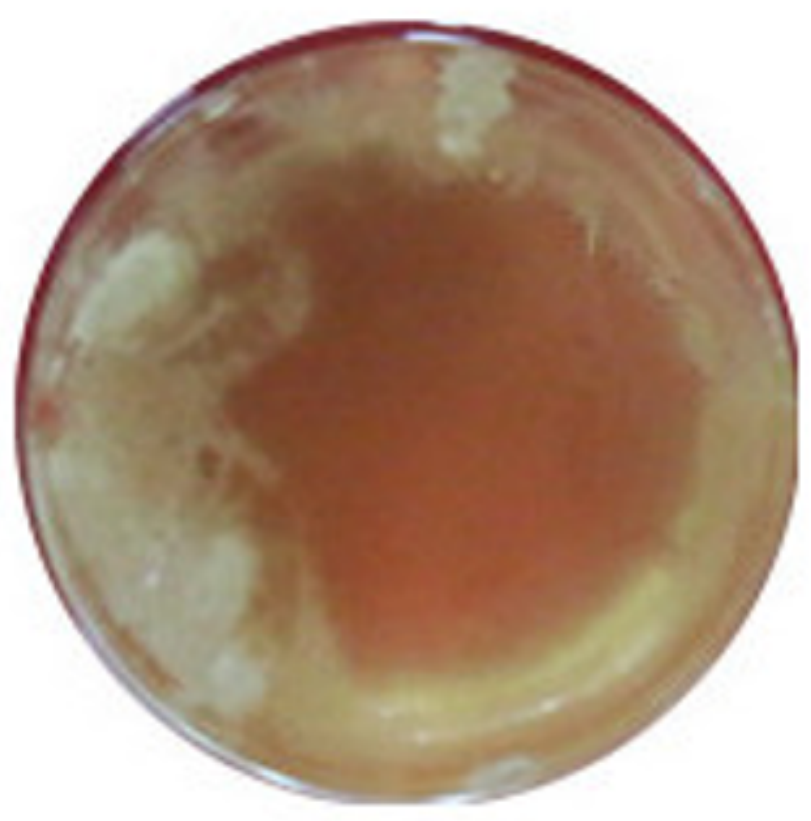

(2)

\section{Figure 2}

Biofilm morphology diagrams of the transcription fusion strains 0-9(PsipW) and $\Delta \mathrm{icdH}$ (PsipW). A: 09(PsipW) B: $\triangle i c d H$ (PsipW) C: Stratified scan diagram of biofilms of strains 0-9(PsipW) D: Stratified scan diagram of biofilms of strains $\triangle \mathrm{icd} H(P \operatorname{Ps} \mathrm{PW})$. 


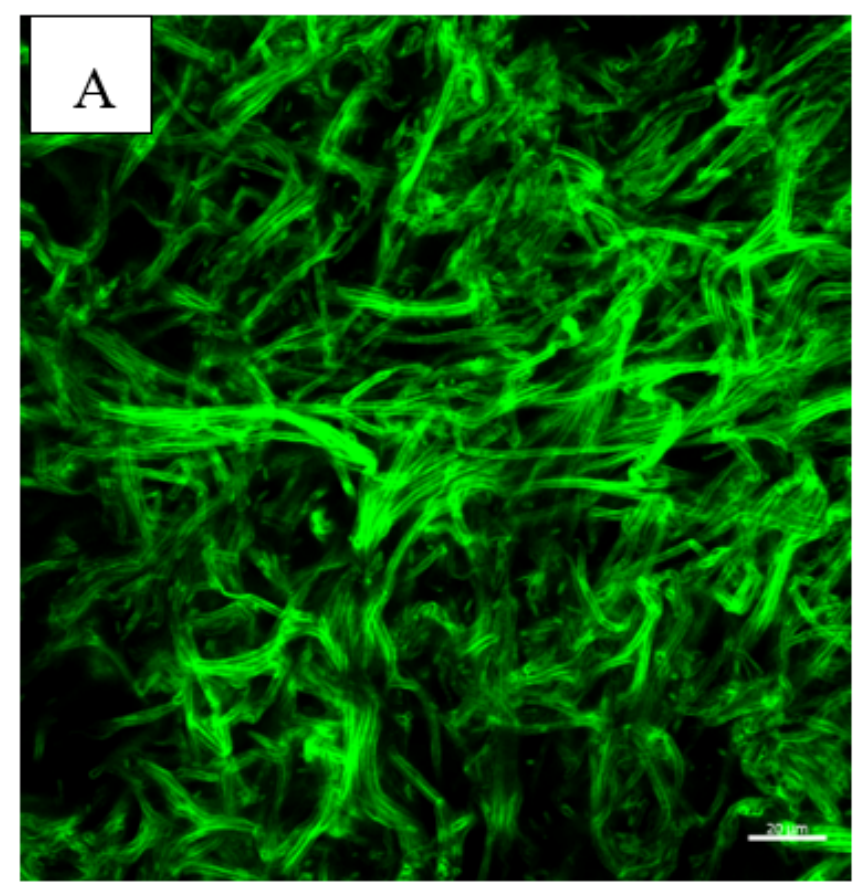

$\mathrm{X}(\mu \mathrm{m})$

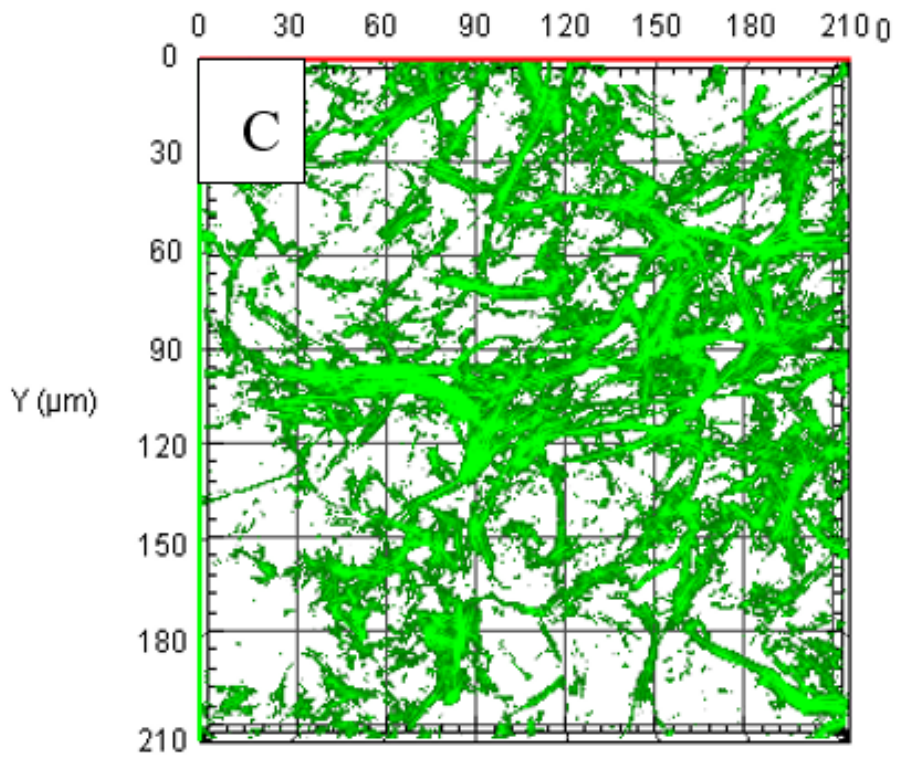

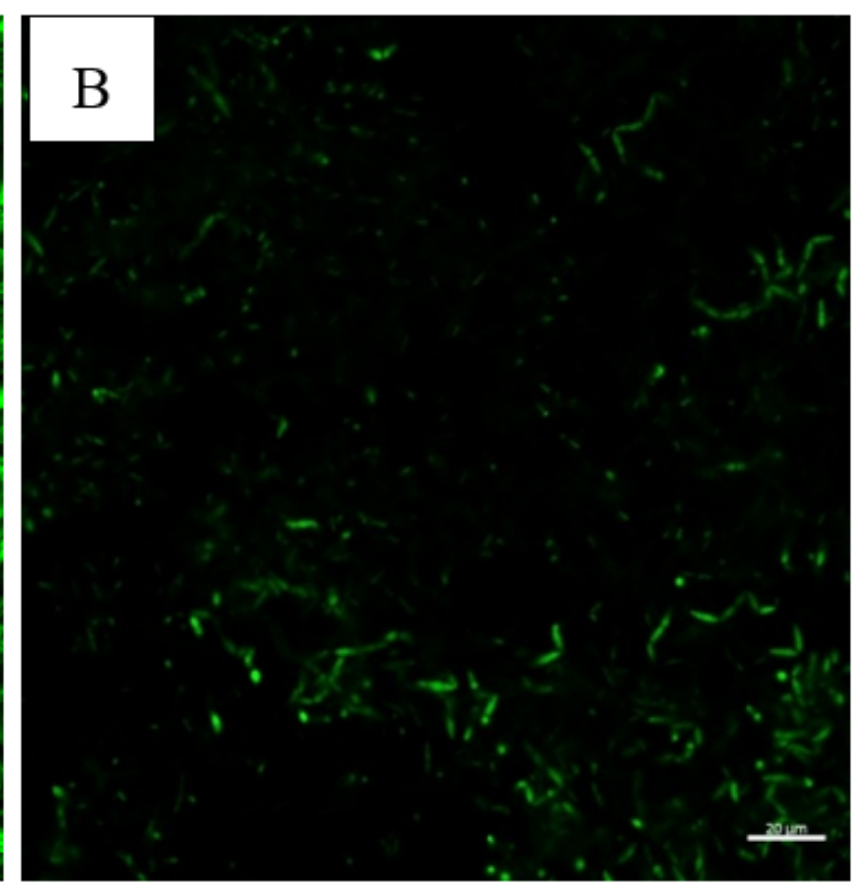

$\mathrm{X}(\mu \mathrm{m})$

$Z(\mathrm{~nm})$

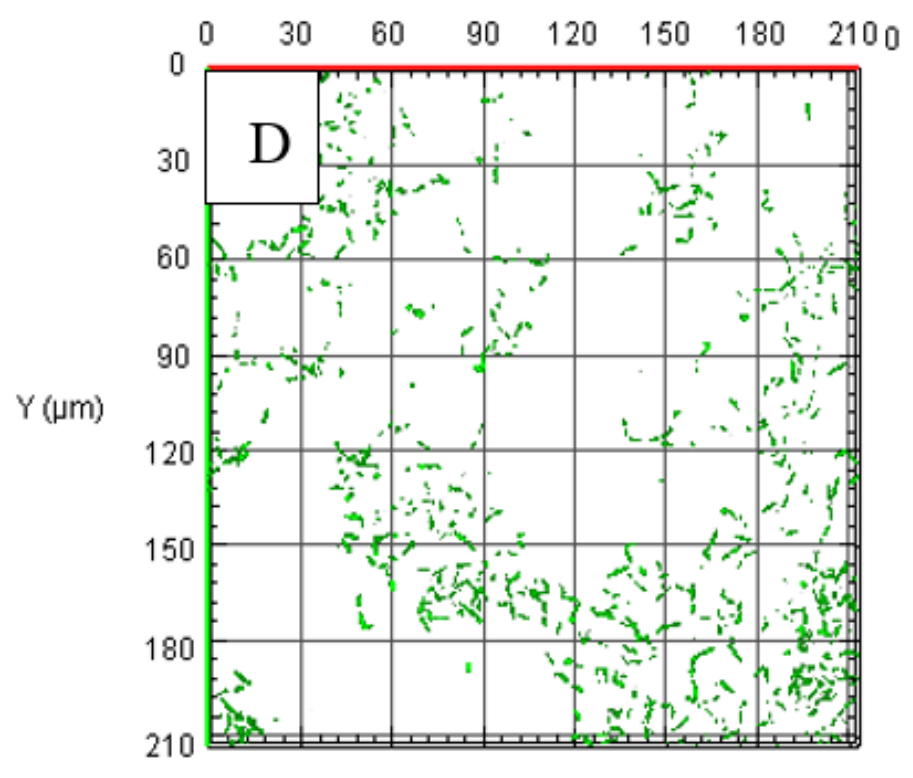

\section{Figure 3}

Biofilm morphology diagrams of the transcription fusion strains 0-9(PsipW) and $\Delta \mathrm{icdH}$ (PsipW). A: 09(PsipW) B: $\triangle i c d H$ (PsipW) C: Stratified scan diagram of biofilms of strains 0-9(PsipW) D: Stratified scan diagram of biofilms of strains $\triangle \mathrm{icdH}(\mathrm{PsipW})$. 


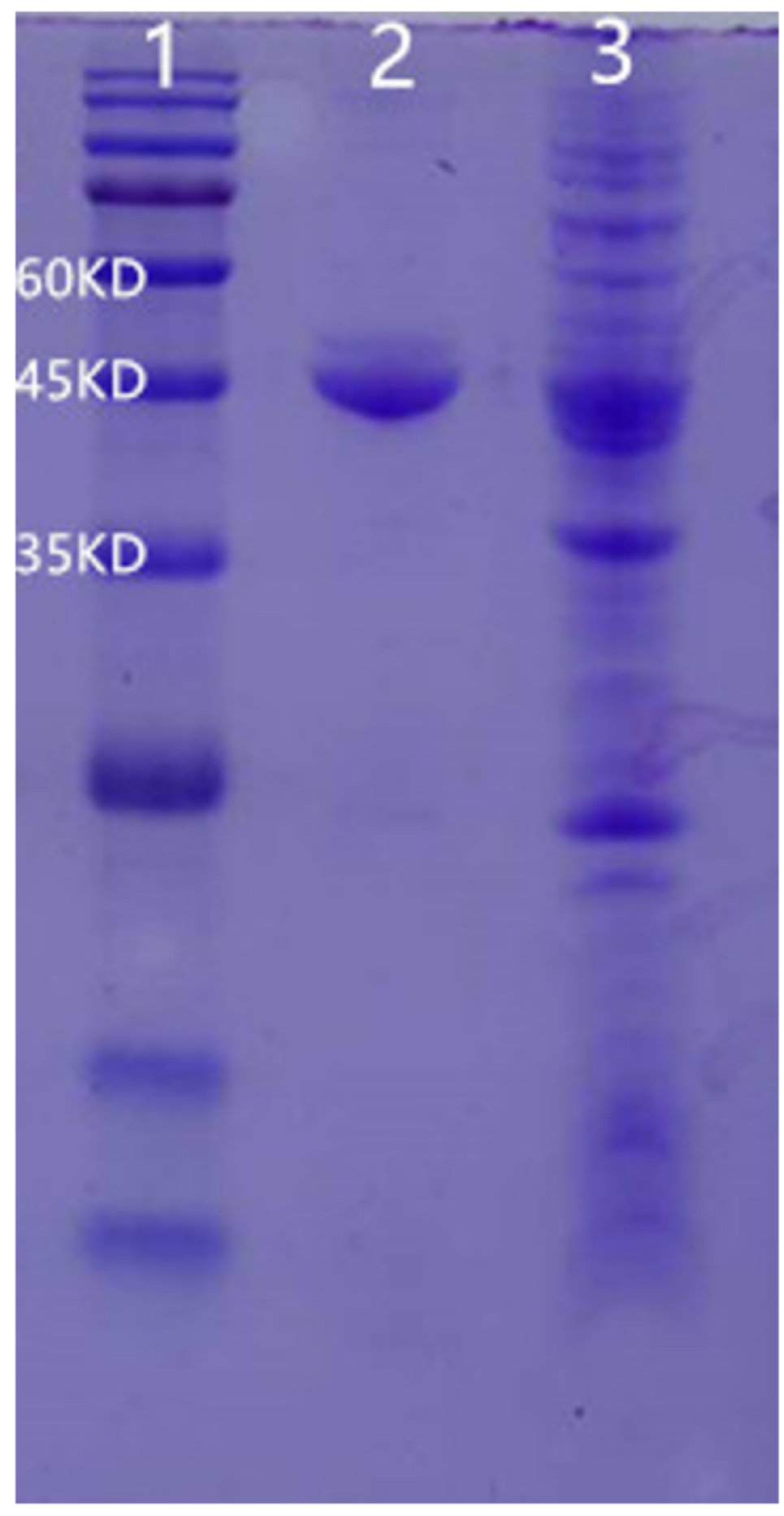

\section{Figure 4}

SDS-PAGE of purified His-tagged IDH protein. Line 1: Marker proteins. Line 2: the purified protein. Line 3: the crude extracts of protein. 


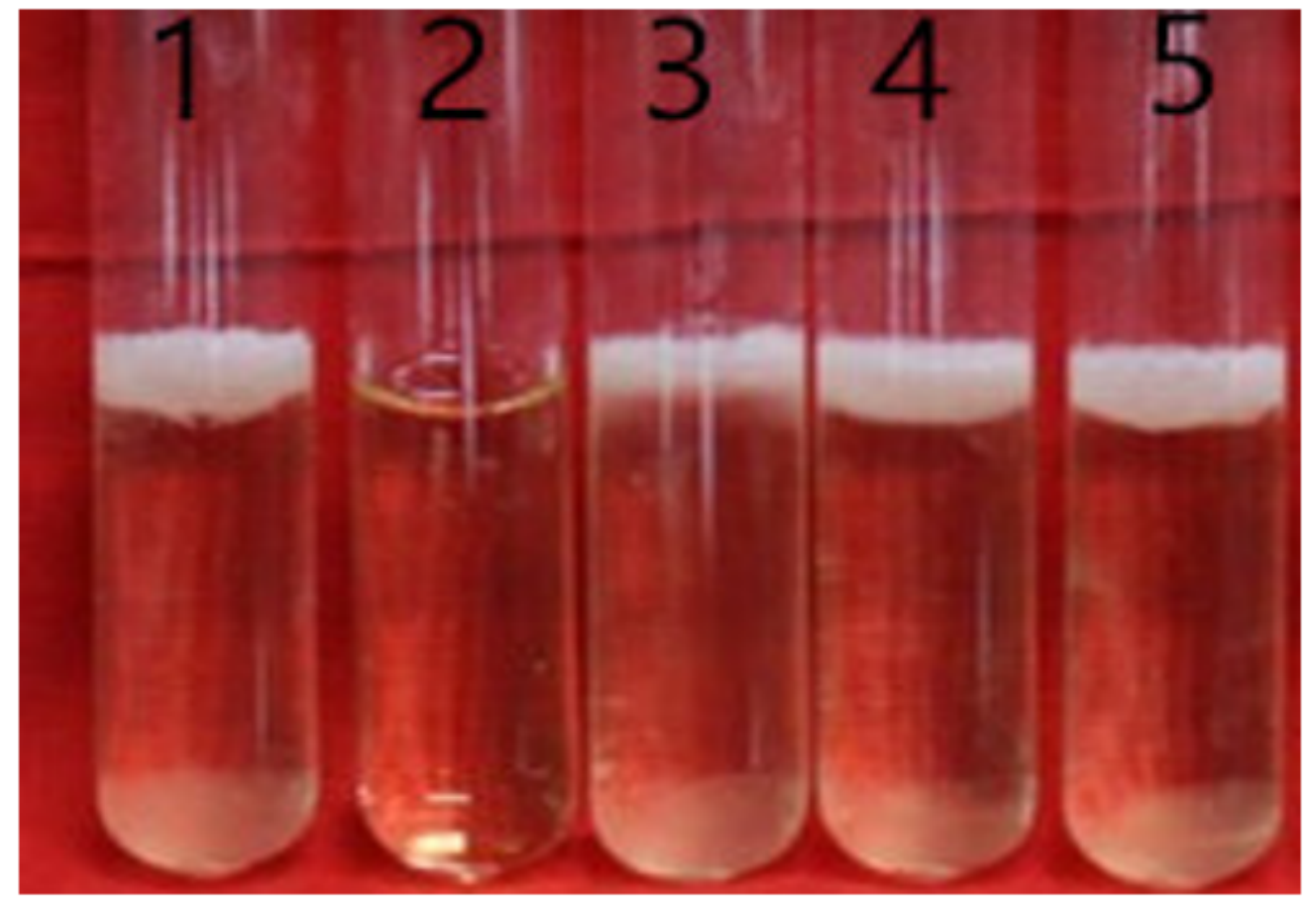

Figure 5

The biofilm results produced by $B$. cereus $0-9$ and the mutant strain $\triangle \mathrm{icdH}$ in LBS and LBS medium supplemented with $0.001 \%$ a-ketoglutaric acid. 1: B. cereus 0-9. 2: Blank. 3: the mutant strain $\triangle \mathrm{icdH}$. 4: $\triangle \mathrm{icdH}:: \mathrm{icdH} .5$ : $\triangle \mathrm{icdH}: \mathrm{icdHBS}$. 


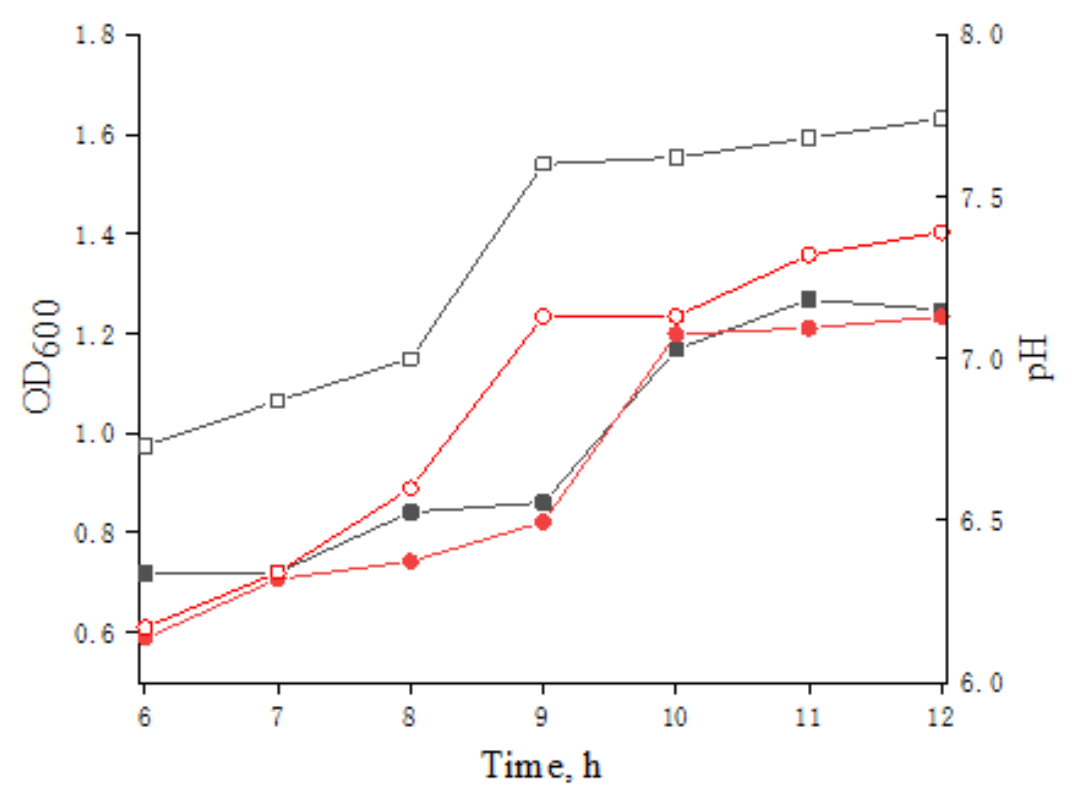

B

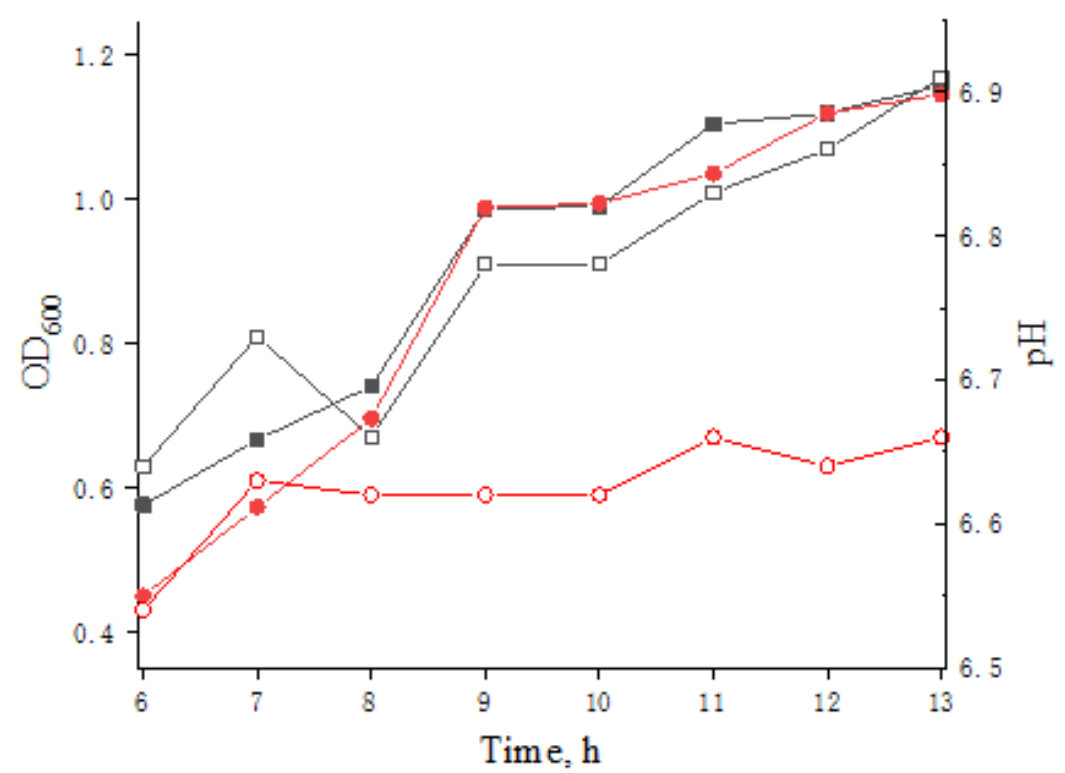

Figure 6

The $\mathrm{pH}$ values of $\mathrm{LB}(\mathrm{A})$ and $\mathrm{LBS}(\mathrm{B})$ medium under different conditions for $\mathrm{B}$. cereus $0-9$ and the mutant strain $\triangle \mathrm{icdH}$. $\square$ : the OD600 value of $\mathrm{B}$. cereus 0-9 0: the OD600 value of the mutant strain $\triangle \mathrm{icdH} \square$ : the $\mathrm{pH}$ value of $\mathrm{B}$. cereus $0-9$ : the $\mathrm{pH}$ value of the mutant strain $\Delta \mathrm{icdH}$ 


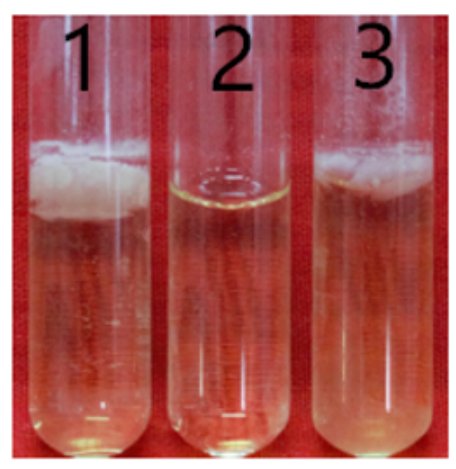

A

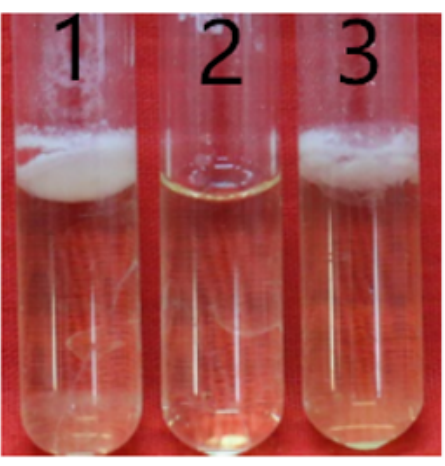

$\mathrm{B}$

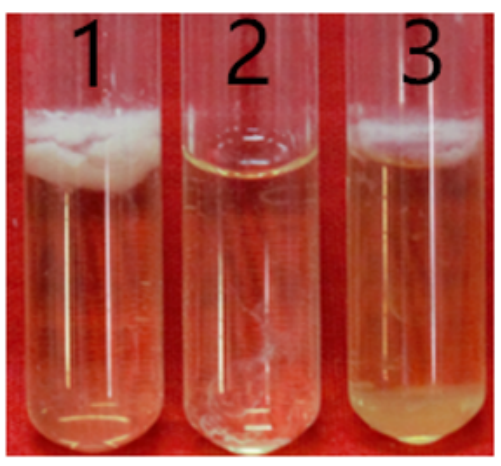

$\mathrm{C}$

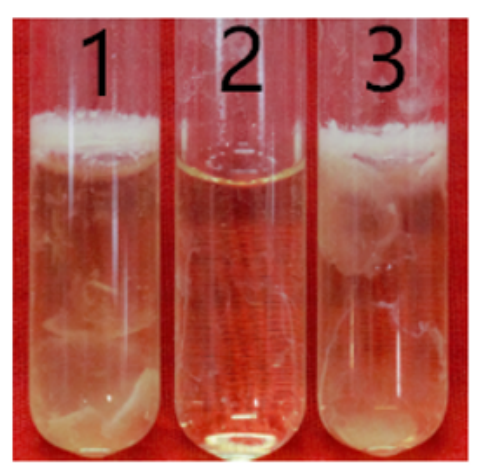

$\mathrm{D}$

\section{Figure 7}

The biofilm results produced by B.cereus $0-9$ and the mutant strain $\triangle \mathrm{icdH}$ in LBS and LBS medium supplemented with different concentration of ferric chloride.1: B.cereus 0-9. 2: CK. 3: the defective strain

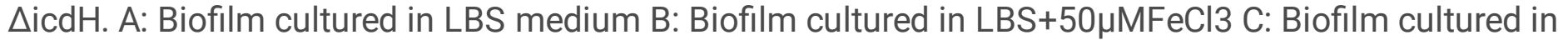
LBS+150 $\mu \mathrm{MFeCl} 3 \mathrm{D}$ : Biofilm cultured in LBS+250 $\mu \mathrm{MFeCl} 3$ 


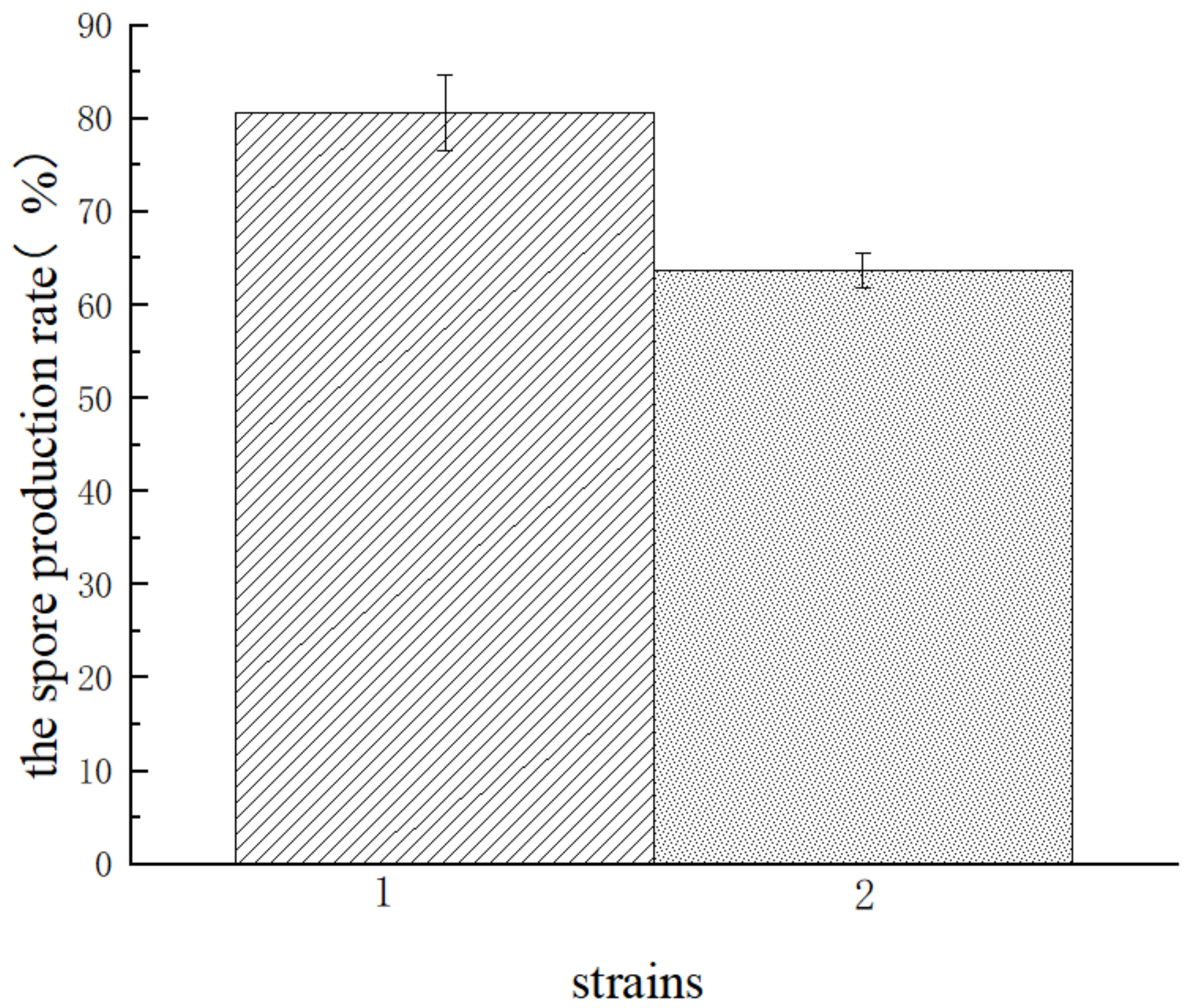

Figure 8

Spore production rate of B.cereus 0-9 and the mutant strain $\Delta \mathrm{icdH} 1$ : B.cereus 0-9 2: the mutant strain $\triangle \mathrm{icdH}$ 